\title{
Idiopathic Granulomatous Gastritis Resembling a Gastrointestinal Stromal Tumor
}

\author{
Hiroaki Niitsu $^{a} \quad K^{2}$ azuaki Tanabe ${ }^{a}$ Noriaki Tokumoto $^{a}$ \\ Takahisa Suzuki $^{\mathrm{a}}$ Asuka Tanaka $^{\mathrm{a}}$ Koji Arihirob \\ Hideki Ohdan $^{\mathrm{a}}$ \\ ${ }^{a}$ Department of Surgery, Division of Frontier Medical Science, Graduate School \\ of Biomedical Science, and ${ }^{\mathrm{b}}$ Department of Anatomical Pathology, Hiroshima \\ University, Hiroshima, Japan
}

\section{Key Words}

Idiopathic granulomatous gastritis - Gastrointestinal stromal tumor - Submucosal tumor Stomach

\begin{abstract}
A 41-year-old female presented with a $2 \mathrm{~cm}$ gastric submucosal tumor that was suspected to be a gastrointestinal stromal tumor or other malignancy, and local resection of the stomach was performed. However, histopathological examination showed granulomatous gastritis (GG) with a variety of chronic inflammatory cells and multinodular granulomas. Although she had a past history of tuberculosis and advanced breast cancer after surgery, there was no apparent evidence of either tuberculosis or a metastatic tumor. Other causes of GG, such as mycosis, syphilis, sarcoidosis or foreign body reaction were also excluded. There were no clinical features of Crohn's disease as the principal differential diagnosis. Therefore, she was diagnosed to have idiopathic granulomatous gastritis (IGG). IGG is rare with few reports, and this report presents a surgical case of IGG resembling a gastrointestinal stromal tumor.
\end{abstract}

\section{Introduction}

Granulomatous gastritis (GG) can be caused by infectious disease (tuberculosis, mycosis, syphilis), sarcoidosis, Crohn's disease, or may be part of vasculitis syndrome [1]. Idiopathic granulomatous gastritis (IGG) is a disorder of the stomach initially described by Fahimi et al. [2], and is only diagnosed when these disease are all 
excluded [1-8]. The actual existence of IGG is debatable [5-7] because IGG is an exclusion diagnosis and fewer than 50 cases have been reported worldwide [4].

On the other hand, there are a wide variety of gastric submucosal tumors (SMTs). The current guidelines [9-11] state that the surgical indications for SMTs include such factors as size of the tumor $>2 \mathrm{~cm}$, the tumor having malignant features, or a pathological diagnosis of gastrointestinal stromal tumor (GIST). It is difficult to make a definitive diagnosis of gastric SMT preoperatively, and sometimes surgical resection and histopathological examination are the only way to obtain a definitive diagnosis.

This report describes a surgical case of IGG resembling GIST that was diagnosed by histopathological examination without any apparent clinicopathological features of the other cause of GG.

\section{Case Report}

A 41-year-old female was followed by CT for advanced breast cancer after surgery, and an abnormal mass of the stomach was found by CT in May 2011. The mass had not been detected by previous CT. She was referred to the Department of Gastroenterological Surgery, Hiroshima University Hospital for further examination and treatment.

The patient had a past history of pulmonary tuberculosis in childhood, peptic ulcer in her 30s, and surgery for advanced breast cancer 3 years earlier (pT4bN2M0, pStage IIIb in UICC classification 7th edition [12], no evidence of recurrence). There was no past history of Crohn's disease, abdominal surgery or trauma.

She had no symptoms, and there were no significant physical findings. Laboratory data showed a normal liver and renal function test, white blood cell count $6,090 / \mathrm{mm}^{3}$ with a normal differential, red blood cell count $4.64 \times 10^{6} / \mathrm{mm}^{3}$, hemoglobin $13.5 \mathrm{~g} / \mathrm{dl}$, hematocrit $40.6 \%$, platelet count $265 \times 10^{3} / \mathrm{mm}^{3}$, and CRP $0.05 \mathrm{mg} / \mathrm{dl}$. Tumor markers were all within normal limits: CEA $2.2 \mathrm{ng} / \mathrm{ml}$ (normal <5.0), CA19-9 $7 \mathrm{U} / \mathrm{ml}$ (normal <37), alpha-fetoprotein $5.9 \mathrm{ng} / \mathrm{ml}$ (normal <10.0), CA15-3 $7.5 \mathrm{U} / \mathrm{ml}$ (normal <30), and CA125 $7 \mathrm{U} / \mathrm{ml}$ (normal <35). A Treponema pallidum hemagglutination test (TPHA) was positive, but a serological test for syphilis (STS) was negative.

CT showed a mass lesion measuring about $2 \mathrm{~cm}$ in diameter at the antrum of the stomach (fig, 1 ). There was no evidence of recurrent breast cancer. Small nodules were seen in the left upper lobe of the lung which suggested inflammatory change after tuberculosis. Gastrointestinal fiberscopy showed gastric SMT at the anterior wall to the side of the lesser curvature in the antrum of the stomach (fig. 2a). Endoscopic ultrasonography showed the SMT to be a hypoechoic round mass in the 4th layer (muscularis propria), and the tumor was $23 \mathrm{~mm}$ in diameter (fig. 2b). Upper gastrointestinal radiography showed a $25 \mathrm{~mm}$ smoothly elevated lesion with bridging fold. Total colonoscopy showed no abnormal findings except for mild melanosis of the colon and a few small polyps.

The gastric SMT such as GIST was suspected. SMT was an indication for surgery according to the current guideline for SMT because tumor size was $>20 \mathrm{~mm}$ [9-11]. Laparoscopic resection was selected. Laparoscopy revealed adhesions among the greater omentum, distal part of the stomach and abdominal wall. There were few serous ascites that were negative for malignancy in intraoperative cytology. Despite laparoscopy and intraoperative gastrointestinal fiberscopy, the location of the SMT was unclear. The surgery was converted to an open procedure to palpate and confirm the location of the tumor, and local resection of the stomach was performed. In addition, a swollen lymph node around the SMT was also resected.

Intraoperative rapid diagnosis of both specimens was done by using frozen sections. The SMT appeared to be an inflammatory tumor or abscess, at least negative for malignancy. The resected lymph nodes were also negative for malignancy. The histopathological findings (ig. 3 ) showed a SMT in the muscular layer of the stomach, while also demonstrating coagulation necrosis. There were multinodular granulomas in the SMT, and there were a wide variety of chronic inflammatory cells 
around the granulomas. Based on these findings, the SMT was diagnosed to be GG. We then tried to determine the cause(s) of the GG, such as Crohn's disease, sarcoidosis, a reaction to malignancy, vasculitis or infectious diseases.

In hematoxylin-eosin (HE) staining, there were a few Langerhans giant cells and foreign bodytype giant cells, and there was no caseating necrosis. These findings indicated that the patient was negative for Crohn's disease and sarcoidosis. There was no evidence of malignancy or vasculitis in the specimen. Infectious diseases such as mycosis, Treponema, Helicobacter pylori and Mycobacterium were not detectable by special stains such as Grocott staining, Warthin-Starry staining and Ziehl-Neelsen staining. PCR analysis of the specimen was also negative for tuberculous and nontuberculous mycobacteria.

Based on these results, including the preoperative examination and pathological findings, there were no apparent causes responsible for the GG. We therefore made a final diagnosis of IGG.

\section{Discussion}

GG is a heterogeneous group that must be distinguished from infections such as tuberculosis, mycosis and syphilis, foreign body reaction, vasculitis, granulomas in response to malignancy, Crohn's disease and sarcoidosis [6]. The common causes of GG are shown in table 1 [8].

Some diseases were excluded by the histopathological findings in the current case. Granuloma caused by neoplasia and granuloma characterized by eosinophilic cell proliferation such as parasitic infection, eosinophilic granuloma, and allergic granulomatosis and vasculitis were excluded by the normal HE staining. The negative Grocott stain supported an absence of fungal infection. No fibrotic rims trapping a foreign body-induced granuloma [6] or foreign body itself were detected.

The patient had a past history of syphilis that had been treated by oral ampicillin. Her blood chemistry revealed positive TPHA and negative STS, thus suggesting a previous but inactive syphilis infection. In addition, negative result for the WarthinStarry method supported absence of spirochetes. She had recovered from tuberculosis over 30 years before, so granuloma due to tuberculosis was a candidate for differential diagnosis. However, the histopathological findings revealed few epithelioid cells, Langerhans giant cells or foreign body-type giant cells. In addition there were no caseating necroses. These findings suggested a negative association with tuberculosis (or other mycobacterial infection), but the evidence was insufficient for exclusion, so she was further examined by PCR, which is the most sensitive and specific examination for detecting these mycobacteria. Samples were obtained from deparaffinization section for PCR. The result was negative for tuberculous or nontuberculous mycobacteria.

Sarcoidosis was unlikely because the histopathological findings were not typical for noncaseating granuloma. Furthermore, there were no granulomas outside of the alimentary tract. Crohn's disease was an important candidate when making a differential diagnosis. However, there were no symptoms such as fever, abdominal pain or bloody feces, and no characteristic colonoscopic findings were observed at that time. Although a careful follow-up for Crohn's disease might be needed, there was considered to be little possibility of a diagnosis of Crohn's disease. 
The major histopathological feature of IGG is transmural, noncaseating granulomatous inflammation [8]. In previous reports, noncaseating granulomas consisting of epithelioid cells and Langerhans-type giant cells were seen microscopically $[2-4,6,7]$. The histopathological findings of the present case were different from these reports. However, despite the atypical histopathological findings, other potential causes of gastric granuloma were all excluded, and the final diagnosis was IGG.

There are a wide variety of gross features of IGG, such as multiple ulcers or erosions of the stomach, erythema of the mucosa, gastric wall thickening, polypoid lesions, and so on. When we searched PubMed using 'granulomatous gastritis' and 'submucosal tumor' as the key words, there was only one case report of IGG with SMT and multiple ulcer scars [13]. However, there were no reports of a solitary SMT that had only a gross finding of IGG, as was the case in the present patient. Therefore, IGG resembling a SMT such as GIST is thought to be rare, and to the best of our knowledge, this is the first report of such a case.

In conclusion, we herein report a surgical case of IGG res embling a GIST. SMT such as GIST is often difficult to diagnose preoperatively, and resection and histopathological examination may be the only way to obtain a definitive diagnosis in some cases. When a SMT is encountered, GG should therefore be included in the differential diagnosis. If the pathological diagnosis is GG, the causes of the disease should be identified, such as infectious diseases, foreign body reaction, Crohn's disease and sarcoidosis, and when all causes are excluded, a diagnosis of IGG can be made.

\section{Disclosure Statement}

The authors have no conflict of interest. 
Table 1. Common causes of GG

\begin{tabular}{|c|c|}
\hline Infectious & \\
\hline Bacterial & syphilis \\
\hline & mycobacterial infection \\
\hline & Whipple's disease (rare) \\
\hline & Helicobacter pylori (not typical) \\
\hline Fungal & histoplasmosis \\
\hline & South American blastomycosis \\
\hline & phycomycosis (rare) \\
\hline & Cryptococcus \\
\hline & coccidioidomycosis \\
\hline Parasitic & anisakidosis \\
\hline & schistosomiasis \\
\hline & strongyloidiasis \\
\hline Idiopathic & Crohn's disease \\
\hline & sarcoidosis \\
\hline & idiopathic GG \\
\hline Miscellaneous & chronic granulomatous disease of childhood \\
\hline & allergic granulomatosis and vasculitis \\
\hline & plasma cell granuloma \\
\hline & tumoral amyloidosis \\
\hline & rheumatoid nodule \\
\hline & gastric perforation \\
\hline & complications of peptic ulcer disease \\
\hline & malakoplakia \\
\hline & granulomas seen in drug addicts \\
\hline Neoplastic & associated with gastric carcinoma \\
\hline & associated with gastric lymphoma \\
\hline & Langerhans cell histiocytosis \\
\hline Foreign body & food \\
\hline & suture \\
\hline & barium \\
\hline & retained surgical sponges or lap pads \\
\hline & talc \\
\hline & beryllium \\
\hline
\end{tabular}




\begin{tabular}{r|l|l|l}
$\begin{array}{r}\text { Case Reports in } \\
\text { Gastroenterology }\end{array}$ & $\begin{array}{l}\text { Case Rep Gastroenterol 2012;6:502-509 } \\
\text { DOI: 10.1159/000341806 }\end{array}$ & $\begin{array}{l}\text { Published online: } \\
\text { July 25, 2012 }\end{array}$ & $\begin{array}{l}\text { @ 2012 S. Karger AG, Basel } \\
\text { ISSN 1662-0631 } \\
\text { www.karger.com/crg }\end{array}$ \\
\hline
\end{tabular}

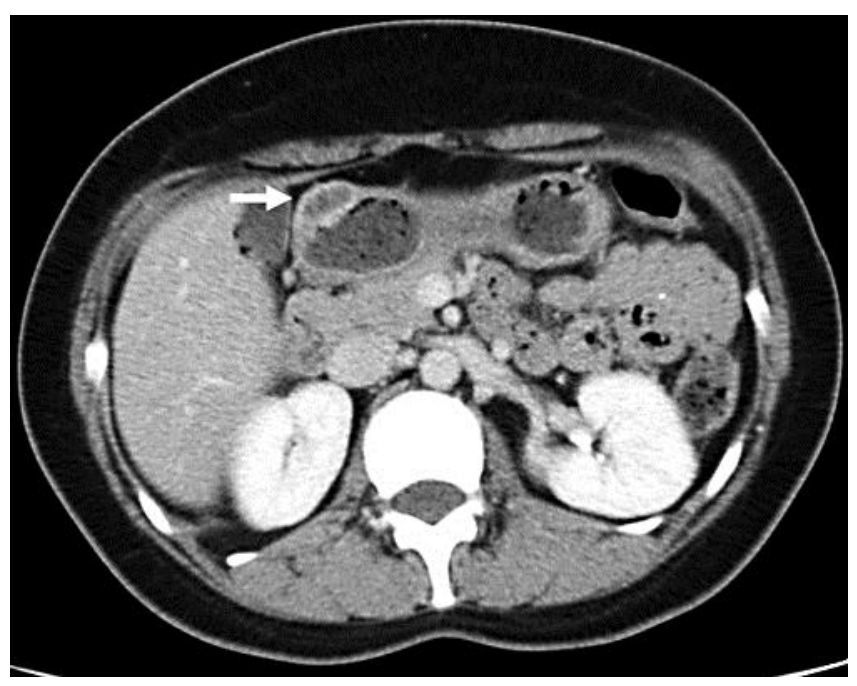

Fig. 1. CT scan showed a mass lesion measuring approximately $2 \mathrm{~cm}$ in diameter at the antrum of the stomach.
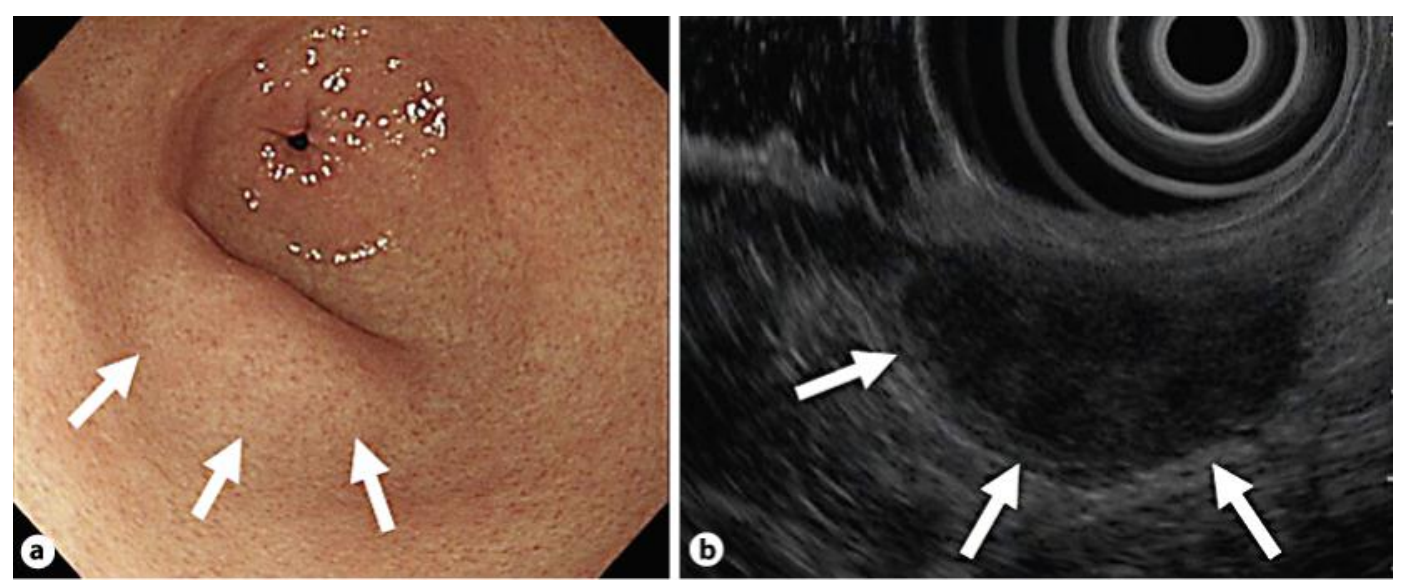

Fig. 2. a Gastrointestinal fiberscopy showed a gastric SMT at the anterior wall to the side of the lesser curvature in the antrum of the stomach. b Endoscopic ultrasonography revealed the SMT to be a hypoechoic round mass in the 4th layer (muscularis propria), and the tumor measured $23 \mathrm{~mm}$ in diameter. 

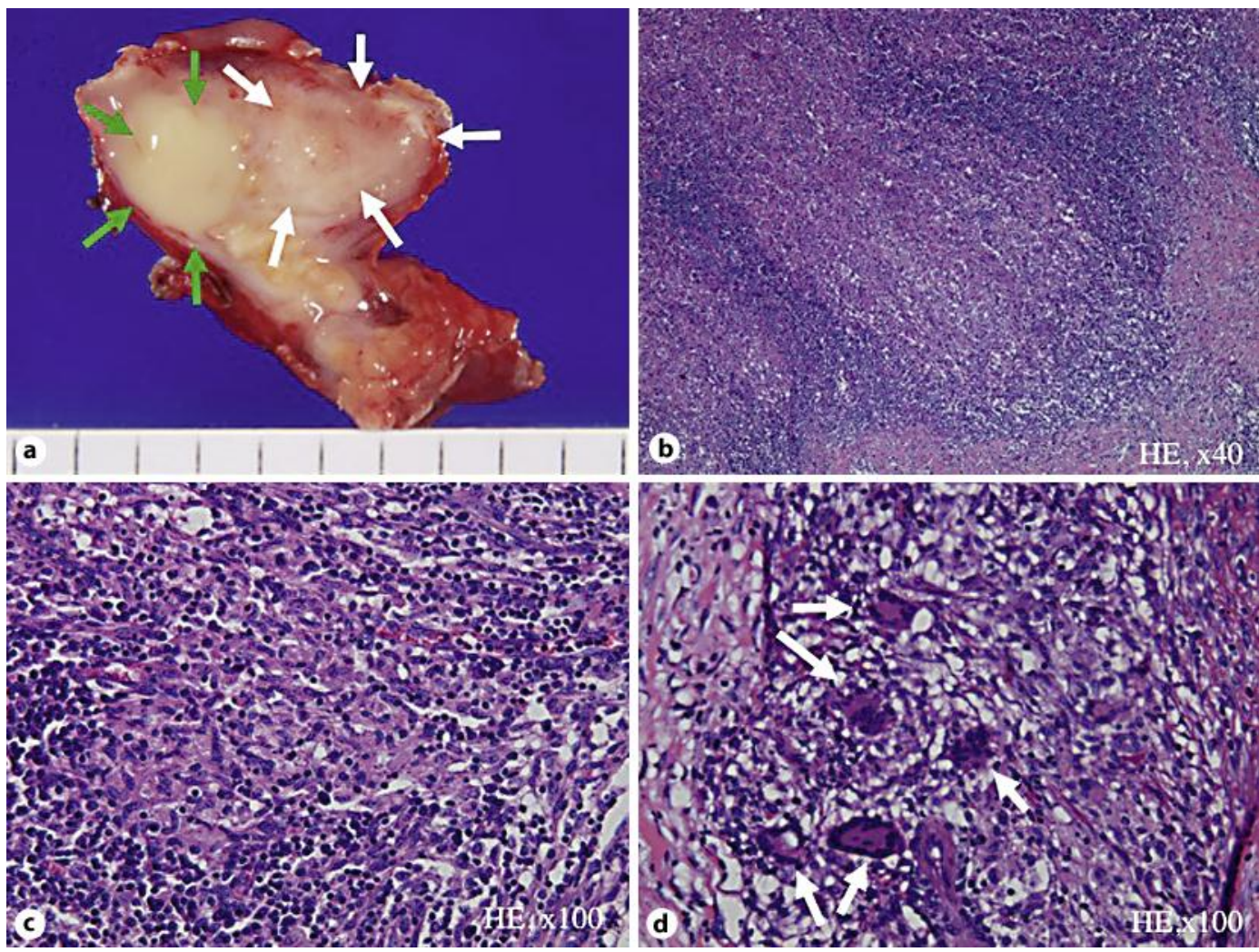

Fig. 3. Histopathological findings of the specimen. a Macroscopic findings. White arrows show granuloma, green arrows show abscess near the tumor. b Multinodular granulomas in the SMT (HE stain, $\times 40$ ). $c$ There were a wide variety of chronic inflammatory cells around the granulomas (HE stain, $\times 100$ ). $\mathbf{d}$ There were a few Langerhans giant cells (white arrows) and foreign body-type giant cells (HE stain, $\times 100$ ), and there was no caseating necrosis.

\section{References}

1 Rosai J, Ackerman LV: Other types of gastritis; in Rosai J (ed): Rosai and Ackerman's Surgical Pathology, ed 9. Edinburgh, Mosby, 2004, p 653.

-2 Fahimi HD, Deren JJ, Gottlieb LS, Zamcheck N: Isolated granulomatous gastritis: its relationship to disseminated sarcoidosis and regional enteritis. Gastroenterology 1963;45:161-175.

-3 Koyama S, Nagashima F: Idiopathic granulomatous gastritis with multiple aphthoid ulcers. Intern Med 2003;42:691-695.

-4 Hirsch BZ, Whitington PF, Kirschner BS, Black DD, Bostwick DG, Yousefzadeh DK: Isolated granulomatous gastritis in an adolescent. Dig Dis Sci 1989;34:292-296.

5 Shapiro JL, Goldblum JR, Petras RE: A clinicopathologic study of 42 patients with granulomatous gastritis. Is there really an 'idiopathic' granulomatous gastritis? Am J Surg Pathol 1996;20:462-470.

6 Sandmeier D, Bouzourene H: Does idiopathic granulomatous gastritis exist? Histopathology 2005;46:352-353.

7 Giacobbe A, Facciorusso D, Cattani L, Tonti P, Andriulli A, Bisceglia M: Does a single granuloma warrant a diagnosis of idiopathic granulomatous gastritis? J Clin Gastroenterol 1993;16:261-263.

8 Noffsinger A, Fenoglio-Preiser CM, Maru D, Gilinsky N: Gastrointestinal Diseases (Atlas of Nontumor Pathology), First Series, Fascicle 5. Washington DC, American Registry of Pathology, Armed Forces Institute of Pathology, 2007, pp 153-158. 
-9 Nishida T, Hirota S, Yanagisawa A, Sugino Y, Minami M, Yamamura Y, Otani Y, Shim ada Y, Takahashi F, Kubota T; GIST Guideline Subcommittee: Clinical practice guidelines for gastrointestinal stromal tumor (GIST) in Japan: English version. Int J Clin Oncol 2008;13:416-430.

10 Demetri GD, von Mehren M, Antonescu CR, DeMatteo RP, Ganjoo KN, Maki RG, Pisters PW, Raut CP, Riedel RF, Schuetze S, Sundar HM, Trent JC, Wayne JD: NCCN Task Force report: update on the management of patients with gastrointestinal stromal tumors. J Natl Compr Canc Netw 2010;8:S1-S41.

-11 Casali PG, Blay JY; ESMO/CONTICANET/EUROBONET Consensus Panel of Experts: Gastrointestinal stromal tumours: ESMO Clinical Practice Guidelines for diagnosis, treatment and follow-up. Ann Oncol 2010;21(suppl 5):v98-v102.

12 Sobin LH, Gospodarowicz MK, Wittekind C: UICC International Union Against Cancer. TNM Classification of Malignant Tumors ed 7. West Sussex, UK, Wiley-Blackwell, 2009, pp 181-193.

13 Yamane T, Uchiyama K, Ishii T, Nakano M, Kanetsuna Y, Okusa T, Tajiri H: Isolated granulomatous gastritis showing discoloration of lesions after Helicobacter pylori eradication. Dig Endosc 2010;22: $140-143$. 